\title{
Distant Metastasis of Gist - A Rare Case Report
}

\author{
Kaur K ${ }^{1}$, Kaur $\mathrm{M}^{2}$, Kundal R. $\mathrm{K}^{3}$, Manisha ${ }^{4}$, Mittal $\mathrm{S}^{5^{*}}$
}

${ }^{1}$ Assistant Professor, Department of Pathology, Govt. Medical College and Rajindra Hospital Patiala, Sangrur Rd, opposite Rajindra Hospital, New Lal Bagh Colony, Patiala, Punjab 147001, India

${ }^{2}$ Associate Professor, Department of Pathology, Govt. Medical College and Rajindra Hospital Patiala, Sangrur Rd, opposite Rajindra Hospital, New Lal Bagh Colony, Patiala, Punjab 147001, India

${ }^{3}$ Professor and Head, Department of Pathology, Govt. Medical College and Rajindra Hospital Patiala, Sangrur Rd, opposite Rajindra Hospital, New Lal Bagh Colony, Patiala, Punjab 147001, India

${ }^{4}$ Junior Resident, Department of Pathology, Govt. Medical College and Rajindra Hospital Patiala, Sangrur Rd, opposite Rajindra Hospital, New Lal Bagh Colony, Patiala, Punjab 147001, India

${ }^{5}$ Junior Resident, Department of Pathology, Govt. Medical College and Rajindra Hospital Patiala, Sangrur Rd, opposite Rajindra Hospital, New Lal Bagh Colony, Patiala, Punjab 147001, India

\section{*Corresponding author: Mittal S}

Gastrointestinal stromal tumors (GISTs) are mesenchymal tumors of the gastrointestinal tract that are most commonly seen in the stomach followed by small intestine and rectum. Malignant potential of GIST is detected in approximately $40-50 \%$ of GIST in small intestine and in about 20-25 \% of gastric GIST which is less and although if it has malignant potential there are very less chances of metastasis. Although GISTs can spread to the liver and peritoneum, metastasis to the iliac region is very rare. Here, we report the rare case of a distant recurrence in the left iliac fossa after diagnosis of GIST with liver metastasis and adjuvant imatinib therapy for one year. 2 years after therapy completion, the patient presented with pain abdomen. Ultrasound imaging revealed a space occupying lesion liver? metastatic, This is the rare case report of a distant metastasis of a GIST in the left iliac fossa after completion of therapy on imatinib.

Keywords: Gastrointestinal stromal tumors (GISTs), liver metastasis, Distant Metastasis, liver.

Copyright $($ C) 2021 The Author(s): This is an open-access article distributed under the terms of the Creative Commons Attribution 4.0 International License (CC BY-NC 4.0) which permits unrestricted use, distribution, and reproduction in any medium for non-commercial use provided the original author and source are credited.

\section{INTRODUCTION}

Gastrointestinal stromal tumors (GISTs) are the mesenchymal tumors of the gastrointestinal (GI) tract, accounting for $1 \%$ to $3 \%$ of all malignant GI tumors. These tumors can develop from interstitial cells of Cajal in the wall of the GI tract [1]. Although GISTs can develop anywhere along the GI tract, 60\%-70\% arise within the wall of the stomach, and $20 \%-30 \%$ arise in the small intestine [2-4]. Approximately 5\% of all GIST cases arise from extraintestinal like mesentery, omentum, and retroperitoneum [5]. Malignant potential is less and although if it has malignant potential there are very less chances of metastasis. Although GISTs can spread to the liver and peritoneum, metastasis to the iliac region is very rare. The general rate of metastasis to liver, bone and lung were $9.19 \%, 0.47 \%$, and $0.76 \%$, respectively [6]. Here, we report the rare case of a distant metastasis in the left iliac fossa after diagnosis of GIST with liver metastasis.

\section{CASE RePORT}

A Case of 45 years male presented with a chief complaint of pain abdomen from 3 months in october
2020 in the Department of Pathology. It was already diagnosed case of GIST with liver metastasis 3 years back took imatinib for 1 year.

Ultrasound revealed space occupying lesion liver? metastasis. A well defined heterogenous predominantly hyperechoic lesion with surrounding hypoechoic halo measuring $4.7 \times 2.9 \mathrm{~cm}$ is having peripheral vascularity. It is suggestive of SOL Liver ? Metastasis.

Two hyperechoic masses in paraaortic and left iliac region. A well defind heterogenous predominantly hypoechoic mass measuring 6.6 x $4.1 \mathrm{~cm}$ seen on paraaortic region with peripheral vascularity on CDFI. Another similar well defined heterogenous predominantly hypoechoic mass measuring $5.7 \mathrm{x} 5 \mathrm{~cm}$ is seen in left iliac fossa anterior to left iliac vessels. It is suggestive of? recurrence?? Nodal mass.

Ultrasound guided FNA done with 22 gauge needle from left iliac mass. On microscopic examination Blood mixed highly cellular smears show cells arranged in cohesive groups, fascicles, sheets 
along with singly scattered. The tumor cells are spindle shaped with ovoid to elongated nuclei having fine nuclear chromatin. Focal nuclear palisading also seen. Also noted loose fibrillar stroma at places. The tumor cells are exhibiting moderate cellular and nuclear pleomorphism. However no necrosis/ significant mitosis seen in the background. Cytological features are favouring Mesenchymal tumor.

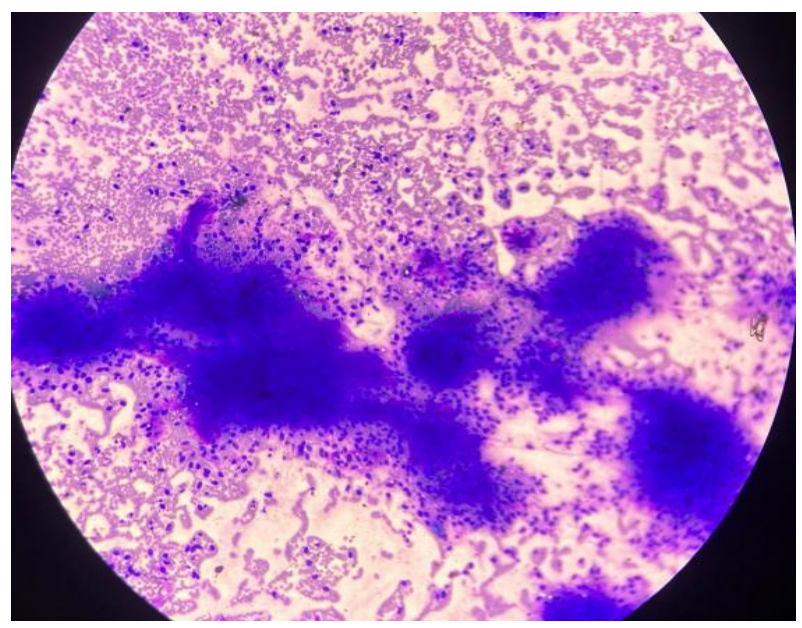

Fig-1: Shows pattern on MGG

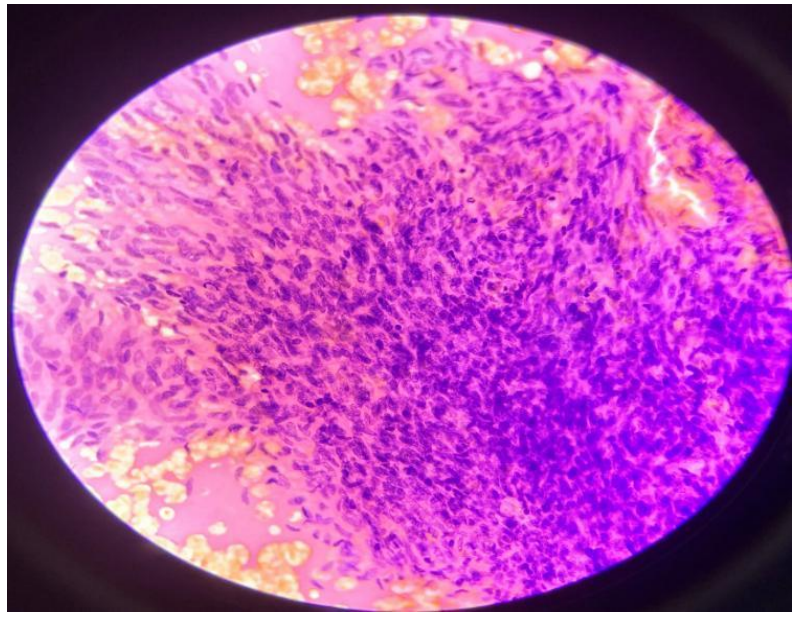

Fig-2: Shows spindle cells on $\mathrm{H \&}$ E

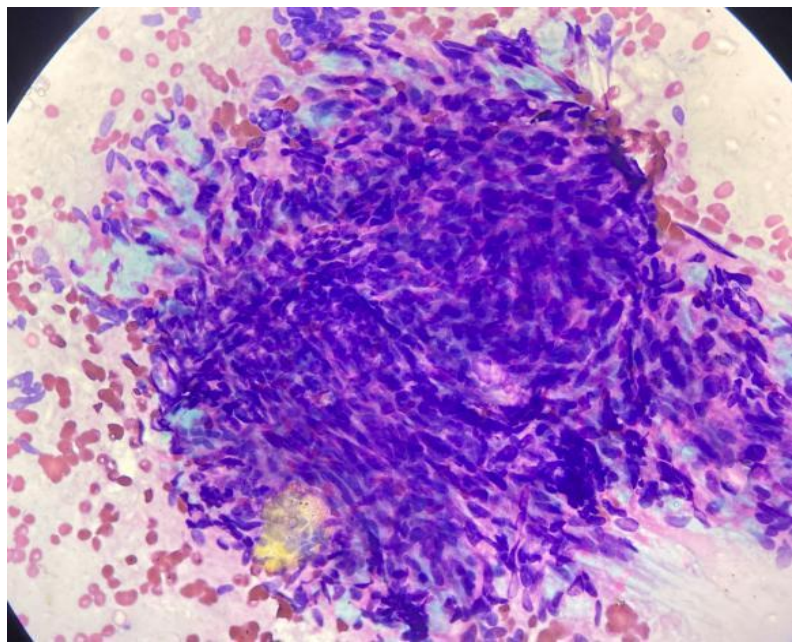

Fig-3: Shows spindle cells on PAP

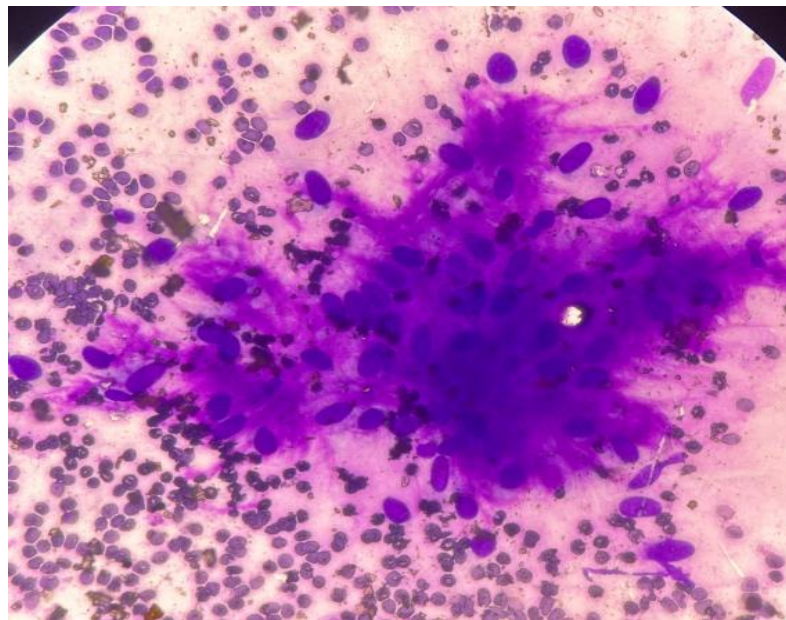

Fig-4: Shows Fibrillar stroma on H \& E

\section{Case Discussion}

Gastrointestinal stromal tumors (GISTs) are the most common mesenchymal tumor of the gastrointestinal tract. Origin of GISTs in the smooth muscle pacemaker interstitial cell of Cajal, or similar cells. They are defined as tumors whose behavior is driven by mutations in the KIT gene (85\%), PDGFRA gene (10\%), or BRAF kinase (rare). 95\% of GISTs stain positively for KIT (CD117). Most (66\%) occur in the stomach and gastric GISTs have a lower malignant potential than tumors found elsewhere in the GI tract.

Gastrointestinal stromal tumors, or GIST tumors, can originate in the stomach, small intestines, colon, esophagus or other soft tissue that makes up the gastrointestinal tract. It is showing a spectrum of benign, borderline and malignant behavior. They are typically spindled but there is also an epithelioid variant showing same antigen profile. Cytodiagnosis of spindle cell variant is relatively simple, showing fascicles of spindled cells with elongated, cigar or comma shapd nuclei, often set in a whispy filamentous background. The epithelioid variant presents greater difficulty, resembling epithelial tumors.the cells are round, cytoplasm distinct with a perinuclear halo and nuclei vesicular.

Gastrointestinal stromal tumors (GISTs) always has a differential diagnosis of other spindle cell mesenchymal tumors such as leiomyoma, schwannoma, and their malignant counterparts. At times, it is difficult to differentiate GIST from these tumors on cytology alone. A panel of immunostaining may be helpful.

The Tumors express CD117 (C kit) and CD34, but are negative for Desmin, S-100 and keratin. Like other types of cancer, GIST tumors range from stage 1 to stage 4 , depending on the extent to which they've advanced. Stage 4 , it is the most advanced stage, includes GIST tumors that have metastasized to distant areas of the body. The general rate of metastasis to 
liver, bone and lung were $9.19 \%, 0.47 \%$, and $0.76 \%$, respectively [6] whereas metastasis is rare wherever present so here our case is a rare presentation having GIST with liver metastasis already diagnosed in 2017 and in 2020 from USG guided FNA from left iliac fossa revealed metastasis in left iliac fossa. Based on validated risk stratification, behaviour in GIST ranges from essentially benign to uncertain malignant potential to malignant. According to biological potential of mesenchymal tumors of digestive system, WHO classification 2013 it is included in malignant category.

\section{CONCLUSION}

It is a rare presentation of GIST metastasis which is rarely diagnosed on cytology.

\section{REFERENCES}

1. Kindblom LG, Remotti HE, Aldenborg F, MeisKindblom JM. Gastrointestinal pacemaker cell tumor (GIPACT): gastrointestinal stromal tumors show phenotypic characteristics of the interstitial cells of Cajal. Am J Pathol. 1998; 152:1259-1269.

2. Corless CL, Fletcher JA, Heinrich MC. Biology of gastrointestinal stromal tumors. J Clin Oncol. 2004; 22:3813-3825.
3. Mucciarini C, Rossi G, Bertolini F, Valli R, Cirilli C, Rashid I, Marcheselli L, Luppi G, Federico M. Incidence and clinicopathologic features of gastrointestinal stromal tumors. A populationbased study. BMC Cancer. 2007; 7:230.

4. Rammohan A, Sathyanesan J, Rajendran K, Pitchaimuthu A, Perumal SK, Srinivasan U, Ramasamy R, Palaniappan R, Govindan M. A gist of gastrointestinal stromal tumors: A review. World J Gastrointest Oncol. 2013; 5:102112.

5. Miettinen M, Monihan JM, Sarlomo-Rikala M, Kovatich AJ, Carr NJ, Emory TS, Sobin LH. Gastrointestinal stromal tumors/smooth muscle tumors (GISTs) primary in the omentum and mesentery: clinicopathologic and immunohistochemical study of 26 cases. Am J Surg Pathol. 1999; 23:1109-1118.

6. Yang DY, Wang X, Yuan WJ, Chen ZH. Metastatic pattern and prognosis of gastrointestinal stromal tumor (GIST): a SEER-based analysis Clinical and Translational Oncology. 2019, 21:1654-1662. 